Liu, Y., Keeling, K. and Papamichail, K. (2015). Should retail trade companies avoid recruiting maximisers? Management Decision 53:730-750. Doi:

10.1108/MD-06-2014-0402.

\title{
Should Retail Trade Companies Avoid Recruiting Maximisers?
}

\begin{abstract}
Purpose - Investigates differences in characteristics, job outcome experiences and attitudes of maximiser and satisficer decision-making style groups working in the retail trade.
\end{abstract}

Design/methodology/approach - Survey conducted using the Amazon Mechanical Turk panel of 140 US participants who have accepted a retail job offer in the past six months. Investigated participants' decision-making style, plus experiences and attitudes toward their present job and the (retail) job information sources used.

Findings - The results show that compared to satisficers, maximisers exert more effort when searching job information, have higher uncertainty avoidance and need for cognition, and experience more post-decisional regret. In this sample, any significant differences between maximisers and satisficers in relation to job satisfaction, company commitment, and intention to quit their present job are restricted to certain groups. For recruitment information sources, while satisficers rely on their families and friends for information, maximisers are more likely to obtain job-related information from other sources such as online discussion forums.

Practical implications - Though some studies suggest that maximisers are unhappy with their choices, this research recommends that retail trade companies should not exclude maximisers from their recruitment pools. Retailers should enhance their candidate pools with both maximisers and satisficers by managing different recruitment information sources, especially with a view to providing realistic expectations.

Originality/value - Research of decision-making style in recruitment is relatively limited. This research illustrates the differences of attitudes between maximisers and satisficers towards their present retail job, and also demonstrates the preferences of maximisers and satisficers in recruitment information sources.

Keywords: Maximiser, Satisficer, Recruitment, Information Source, Decision-making Style, Retail Sector 


\section{Introduction}

Within human resource management, recruiting the right talent is crucial for organisations. This is especially true in the retailing industry, where the turnover rate is relatively high as employees have a lower-than-average income, longer work hours, and some employees do not have high commitment to their organisation, perhaps because they do not consider their jobs in the retailing industry to be lifelong ones (Rhoads et al., 2002). Moreover, switching jobs in the retail sector is easy. The U.S. Bureau of Labor Statistics reveals that in 2013, on average, there were nearly 515,000 job openings every month in the retail trade in the U.S. Breaugh (2013) proposes that one of the best strategies to generate more qualified and suitable candidates for these roles is to increase the number of applicants in the application pool. Recruitment researchers and practitioners have, therefore, devoted much of their time to exploring the ways in which they can utilise different recruitment information sources to disseminate the message about the opening of a job vacancy and to attract a larger number of jobseekers to apply for it (Cable and Turban, 2001).

An individual difference between jobseekers that will affect how they react to the information in job advertisements is their information-seeking and decision-making strategy. A well-known classification of information seeking and decision-making is the concept of 'maximising and satisfying' that originates from Herbert Simon's (1955) work; this has been widely adopted by a variety of researchers and studies (e.g., Schwartz et al., 2002; Schwartz and Ward, 2004; Nenkov et al., 2008; Dar-Nimrod et al., 2009; Lai, 2011; Turner et al., 2012; Sparks et al., 2012). Schwartz et al. (2002) define the terms 'maximiser', and 'satisficer', and explain that maximisers prefer to compare and research an object, such as a product, as much as possible, and evaluate and analyse information carefully to make the best choice. In contrast to this, those who adopt an alternative decision-making style are named satisficers and are characterised having low maximising tendency, and preferring to seize chances and possibilities when they arise instead of spending time on acquiring information. Satisficers do not strive to make the 'best decision' and will settle for a 'good-enough' decision. Maximisers generally put a great deal of effort into searching for information. They are known to hold self-imposed high standards regarding the outcomes of the decisions that they make but also find it more challenging than 
satisficers to make a 'final' decision (Schwartz et al., 2002). Given these tendencies, satisficers are more likely than maximisers to find the information in job advertisements to be sufficient to make a decision, so one way to maximise the pool might be to give more information about vacancies in the initial messages and attract more maximisers.

Logically, the more careful, information-collecting maximisers should perform better than satisficers in decision-making activities because of these positive characteristics and be more content with their choices. Hence, attracting more maximisers could have beneficial effects on staff retention and performance. Nevertheless, there is some research indicating this may not be the case and that there could be risks involved in employing maximisers. For example, recent research confirms that maximisers display higher post-purchase regret, and feel unhappy and dissatisfied with their choices (Lai, 2011; Polman, 2012), and in consequence, favour retaining the possibility to revise their choices (Sparks et al., 2012). Thus, maximisers have lower commitment to their choices (Sparks, Ehrlinger and Eibach 2012) and continue to look for the 'perfect' option. Parker et al.'s (2007) study reveals that maximisers always consider there is a better choice than the present one. This conflict about making decisions and focus on the decision that they are facing (Misuraca and Teuscher, 2013) may mean that maximisers are still undecided at the time of decision deadlines. This actually leads to them to have to make time-pressured decisions when the deadline comes that are therefore more spontaneous. As a result, they may feel they have not been able to gather all information, or evaluate the choices rationally, and so they might be less committed and convinced about the choice (Sparks, et al., 2012). In comparison, satisficers consider fewer criteria and do not like to waste time gathering information. Satisficers usually make their choice once they have found one that satisfies their needs, even though better choices may exist.

As much of the existing research reveals that maximisers are a group who can be difficult to satisfy, may make spontaneous decisions when deadlines loom, and are more likely to be unhappy and regret with their choices, this poses the question: should recruitment managers change their strategies to widen the pool by attracting more maximisers, or should these maximiser-style jobseekers be avoided when retail companies need to recruit new employees that will be content at work and stay with 
them? Rapid turnover of staff increases costs, and unhappy staff are unlikely to perform well. Furthermore, do satisficers have higher levels of job satisfaction, a higher level of loyalty to the company than maximisers after they accept the issued offer and get to work? This is an underexplored area. Much of the work relating decision-making style to job search has utilised student samples and long-term vocational job choice mostly free of locational or other restrictions on choice set. Relatively few studies have discussed the characteristics of maximisers and satisficers within specific domains, such as whether maximisers can or cannot make satisfying job choices, compared to those of satisficers, in the retail trade. In this instance, although there may be many vacancies nationally, non-student job seekers are less likely to be able to take a job in any location. They are more likely to be limited to jobs within their immediate vicinity, and also restricted by a lack of variation in income and other conditions between employers. Moreover, retail jobs are more likely to have short application deadlines, restricting maximiser search time. This research aims to investigate whether maximiser and satisficer styles affect jobseekers who want to work in the retail trade and if they have different attitudes towards their decisions and their experience about the job. A follow-up question is whether maximisers and satisficers have different recruitment information source preferences when they research a job vacancy in the retail trade. Recruitment managers may focus on which recruitment sources satisficers or maximisers prefer and use these to attract jobseekers who adopt satisficer or maximiser strategies during a job-related information search.

\section{Literature Review and Hypotheses}

Even though the classification of maximiser and satisficer has been adopted in a variety of studies in different areas (e.g., Schwartz et al., 2002), a very limited amount of research has applied it in the field of recruitment, particularly in the retail trade (Breaugh, 2013). Gruszka, Matthews, and Szymura (2010) indicate that individual differences and personal characteristics have their basis in human cognitive functioning and will influence individual attitudes and behaviours. As an exploratory study, the present research examine the relationships between cognition-based variables, including uncertainty avoidance, post-decisional regret (PDR), need for 
cognition (NFC), self-efficacy, effort invested into (job information) researching, and an individual's maximising tendency. These variables are widely adopted and tested in individual differences psychology studies (e.g., Cacioppo and Petty, 1983). Moreover, the study also investigates the current retail trade employees' attitude towards their present job and their previous job-searching experience (met expectations (ME), job satisfaction, company commitment, and intention to quit).

Maximiser and satisficer, as two information-seeking types, illustrate two well-known early theories extant in the social psychology literature. Heider (1958) proposes the theory of 'naïve scientist', which posits that people naturally act like scientists who carefully search for information, weigh costs, evaluate benefits, and attempt to match their expectations. In contrast to this view, Fiske and Taylor (1984) propose that people act as 'cognitive misers', utilising mental short cuts to make assessments and decisions. Acting as a cognitive miser is a protection of mental processing resources that finds different ways to save time and effort when negotiating with the numerous choices faced in daily living. For any individual, these two cognitive approaches may be employed as befits circumstances and contexts, for instance, additional search and evaluation for more important decisions. However, people will differ in their experience and learning of the efficacy of applying each approach. Thus, people may come to rely on and apply one approach more consistently than the other, along with any other cognitive strategies and habits that have become associated with it.

Applying the concepts of naïve scientist and cognitive miser to those of maximising and satisficing, it is likely that maximisers tend to adopt the approach of the naïve scientists; they do not make decisions easily based on only one information clue from one source. Satisficers could be considered to be cognitive misers. They prefer not to put too much effort into decisions if the results cannot be easily predicted. Given a haystack with needles of varying sharpness, maximisers would be willing to search the entire search space to find the sharpest one whereas satisficers would stop their searching efforts once they find a needle that is sharp enough (Simon, 1975). Lai's (2011) study also shows evidence that maximisers are more willing to spend time on receiving information about new services. They are prepared to use resources such as time to establish a larger number of alternatives (Dar-Nimrod et al., 2009). 
Therefore, it is expected that the self-reported maximisers will put more effort into searching for retail trade job-related information than satisficers.

H1. Maximisers will report more effort in searching for retail trade job-related information than satisficers.

Hofstede (1994) defines uncertainty avoidance as the extent to which people are threatened by uncertain or unknown situations. Driver and Mock (1975) indicates that individuals are different in their approach to risk-taking while making decisions. Decision-makers who tend to avoid uncontrolled situations are more willing to put effort into the decision process (Driver and Streufert, 1969). In the face of uncertain gambles, maximisers have been shown to perform less well (Jain et al., 2013). With the characteristics of trying to research as much as possible before committing to a final choice so that they do not make a poor decision, analysing information rationally, and comparing choices carefully (Schwartz et al., 2002), it is anticipated that maximisers may prefer to avoid uncertainty.

H2. Compared with satisficers, maximisers will report a higher preference for avoiding uncertainty when searching for retail job information.

Schwartz et al.'s (2002) research finds a significant positive relationship between maximising tendency and PDR, showing that maximisers generally have a higher degree of regret over the decisions they make. Maximisers always consider that there may have been better choices than the one that they made which resulted in the current position that they hold, and feel regret about what they might have missed. In the retail trade, many vacancies are waiting to be filled; finding a job is not that difficult compared to other sectors that might have relatively higher skill requirements (Ryan, Horvath, and Kriska, 2005). Time is obviously an important factor that may push jobseekers to make choices. Compared with satisficers, who will settle for a 'good-enough' decision, those striving to make the 'best decision', maximisers, are more likely to need to compromise on decisions to meet the deadlines (Parker et al., 2007). Within the limited time, it is not possible to get all vacancy choices and details. At the same time, especially in the retail trade, many job opportunities provide similar offers to new employees (Breaugh, 2013), making it difficult to separate them on 
choice criteria. Hence, it can be expected that maximisers will report higher job decision regret behaviour than satisficers.

H3. In the retail trade, maximisers will report higher PDR behaviour than satisficers.

Bandura (1977) posits that individuals with higher self-efficacy are more likely to show higher confidence to fulfil the tasks they face. As discussed in the previous paragraph, maximisers may tend to spend more effort on the decision-making process and do more information comparisons. However, they are more likely to feel regret about their choices. This reflects that, generally, maximisers may actually have less confidence about their choices because they cannot make up their minds easily, even though much effort has been devoted to the process. On the contrary, satisficers may feel more self-efficacy than maximisers since they experience less conflict about decision-making, meaning they feel a good-enough decision can satisfy their needs and so are not searching for the elusive 'perfect' decision (Schwartz et al., 2002). Moreover, they are not driven to make compromise decisions because they run out of time (Parker et al., 2007).

H4. In the retail trade, satisficers will feel more self-efficacy than maximisers.

Moreover, Cacioppo et al. (1983: 197) define the NFC as 'a need to structure relevant situations in meaningful, integrated ways' and 'an individual's tendencies to seek and engage in effortful cognitive activity'. Higher NFC is associated with complex problem-solving. Higher NFC individuals show higher intentions towards elaboration. Lower NFC individuals may display opposite tendencies and be more likely to process information heuristically (Escalas, 2007). By considering the theories of naïve scientists and cognitive misers, the Elaboration Likelihood Model (ELM) suggests that cognitive misers, those who tend to shorten decisions and use the peripheral path while facing problems, will have a lower NFC because they simplify the received information and choices. Naïve scientists who follow the central path to deal with decisions have a higher NFC since they generally evaluate information in more depth and make simple choices complex (Griffin, 2006). Thus, we anticipate that maximisers will have a higher NFC compared to satisficers. Thus, in our sample of people in the retail sector: 
H5. Maximisers will have a higher NFC than satisficers when seeking job information.

For investigating current employees' attitude towards their retail trade jobs, we expect that maximisers are more likely to report that their present job has met their expectations because they are liable to spend more time and effort in searching for job-related information. The more information they obtain, the more it will enhance their knowledge of the job position and the company, and so their expectations should be more accurate (Wotruba and Tyagi, 1991). Therefore, maximisers are more likely than satisficiers to find the job meets their expectations.

H6. In the retail trade, maximiser-style jobseekers will report higher met job expectations than satisficers.

Notwithstanding, Wotruba and Tyagi (1991) argue that ME do not directly play a complete mediating role in job satisfaction. In other words, ME are not the only or main reason that leads to a higher level of job satisfaction. A characteristic of maximisers is the tendency to PDR; thus, no matter the level of ME, they are more inclined to feel not satisfied with their present job because they may consider there is a better one. Their tendency to use time resources to establish a larger set of options makes them less satisfied with their final choices (Dar-Nimrod et al. 2009). Given the opportunity, they are more likely to reconsider their selected options (Chowdhury et al., 2009) In these circumstances, satisficers might experience a higher level of job satisfaction than maximisers.

H7a. In the retail trade, satisficers will report a higher level of job satisfaction than maximisers.

Further, job satisfaction is positively correlated to company commitment and negatively correlated to the intention to leave the present job (Raymond and Mjoli, 2013; Cook et al., 1981). Company commitment measures an employee's loyalty to the organisation for which they work. Reasonably, when an employee experiences satisfaction in their work, they have higher commitment to the company they work for and are more inclined to remain in that job. Hence, it is anticipated that satisficers will 
have a higher commitment to the company and lower intention to leave their present retail jobs. Therefore, regarding their present retail trade job compared to maximisers:

H7b. Satisficers will have higher commitment to the retail trade company that they currently work for.

H7c. Satisficers will have lower intention to quit their present retail trade job.

Moreover, even though increasing the number of applicants in the application pool is a useful strategy to increase the number of qualified and suitable candidates (Breaugh, 2013), and many researchers have attempted to investigate how different recruitment information sources can have a different impact on jobseekers' job decisions, the proposed suggestions do not reach a consensus. Some researchers (e.g., Hill, 1970) claim that the formal (company-dependent) sources such as newspaper advertisements are less effective than the informal (company-independent) sources (e.g., word-of-mouth from family/friends) as the latter contain more personal and experience-based information and can assist jobseekers in understanding the reality of the actual work environment. In contrast, Cable and Turban (2001) indicate that company-controlled recruitment sources have high adoption by jobseekers, particularly when the information is officially released by the employers and this information is more objective than the experience-based word-of-mouth messages.

Judge and Cable (1997) propose that although previous research has investigated the effects of different recruitment sources or activities on jobseekers, few researchers have considered the aspect of jobseekers' individual differences and personal preferences. Jobseekers may have different preferences in adopting information sources while searching for job information and have different considerations of the information content. Thus, it is expected that maximisers and satisficers differ in recruitment information source preferences when they research a job vacancy in the retail trade, which moderates the effectiveness of different recruitment information sources.

H8: Maximisers and satisficers will have different preferences for use of recruitment information sources while researching job vacancy information in the retail trade. 


\section{Method}

\subsection{Samples}

One hundred and forty (140) participants were recruited from Amazon Mechanical Turk (AMT). Recent research demonstrates AMT as a reliable data collection source (e.g., Buhrmester et al., 2011). It is one of the sites of Amazon Web Services, which is a coordinating Internet marketplace that enables individuals and businesses to offer a small reward to potential respondents to take part in surveys and research. The method is similar to the more common process of collecting questionnaire data from a commercial online research panel; however, the researcher has a more direct contact with, and control over, the respondents. Requesters set the level of reward for each participant and pay Amazon 10\% commission on the price of successfully completed tasks. Researchers set their own criteria for filtering specific participants to take part in the survey; only those qualified to join the study can view the study posts. These include characteristics not normally under control of the researcher, such as frequency of previous survey completion and ratings of provided data quality by previous researchers. AMT members are known as 'workers' but are not employed by Amazon although Amazon runs a strict censoring system to manage its panel members so that they ensure the quality of their participant database. Each participant is only paid after the survey is completed and survey requesters are satisfied with the data quality.

For the present study, we aimed to explore maximisers' and satisficers' characteristics, preferences and experiences in the retailing industry. Only participants who had accepted a job offer in the retail trade in the past six months in the U.S. were selected to join the survey; six months is considered critical for a newly hired employee to stay in the organisation or choose to leave (e.g., O'Reilly, et al., 1989). Participants agreed to show a (job) proof when necessary. Moreover, participants were limited to those who had reached the 'Master level' (the top level of Amazon's membership system) to ensure they had a history of valid survey completion. Ten U.S. dollars were given to each participant via AMT as an incentive after finishing the survey. The data were anonymised; participants can only be identified and contacted by their AMT IDs. 
Table 1 presents the sample demographics; there is a good gender split and the age ranges were all well represented. $43 \%$ of the participants had a high-school degree. Over $91 \%$ of the participants had over one year's past work experience in the retail trade. $67 \%$ received a salary below $\$ 3,000$ U.S. dollars monthly, which corresponds with the salary level in the retailing industry and also reflects the amount of part-time work. Moreover, participants report working in a variety of firms that cover different stores, including clothing (e.g., H\&M, Abercrombie \& Fitch), shoes (e.g., VANS), PC games and computers (e.g., Best Buy, ComputerCity), jewellery (e.g., Fine Jewellery), fast food (e.g., Domino's, Ample Hills Creamery), beauty (e.g., Sally Beauty), gas (e.g., Shell), spectacles (e.g., LensCrafters), groceries (e.g., Walmart, Target, Costco), cars (e.g., Ford), cafés (e.g., Starbucks), furniture (e.g., IKEA), telecommunications (e.g., AT\&T), books (e.g., Bookstone), and music (e.g., Record Town). Thus, the sample covers a wide variety of employers in the retailing industry. This allows for a heterogeneity of experiences that makes less likely any systematic bias from a specific set of employees with particular experiences, which may affect the perception of job satisfaction of those with different decision-making styles.

--- Table 1 about here ---

\subsection{Variables and Measurements}

\section{Self-reported Maximising Tendency}

The 6-item Maximisation Scale (MS)-short provided the evaluation for the individual participants' decision-making style. This is a shortened version of the original 'Maximisation Scale' developed by Schwartz et al. (2002). Nenkov et al. (2008) compare the reliability and the validity of the original 13-item, the 9-item, and the 6-item version of the scale, concluding that the 6-item Maximisation Scale performs best and should be used by future researchers. Three components are included: alternative search questions, 'When I am in the car listening to the radio, I often check other stations to see if something better is playing, even if I am relatively satisfied with what I'm listening to' and 'No matter how satisfied I am with my job, it's only right for me to be on the lookout for better opportunities'; decision difficulty, 'I often find it difficult to shop for a gift for a friend' and 'Renting videos is really 
difficult. I'm always struggling to pick the best one'; and high standards, 'No matter what I do, I have the highest standards for myself' and 'I never settle for second best.' All scale items are anchored at 1 as 'strongly disagree' and 7 as 'strongly agree'.

\section{Effort Invested into Researching Job - related Information}

To explore whether maximisers put a greater deal of effort into researching job options and information than satisficers, four adapted items measured job-search intensity based on Blau's (1993) research. The statements were 'I spent a lot of time looking for a job alternative', 'I devoted much effort to looking for other job options', 'I focused my time and effort on job-search activities', and 'I gave my best efforts to find a job.' (7-point scale: 1 as 'strongly disagree' and 7 as 'strongly agree')

\section{Uncertainty Avoidance}

Five items proposed by Quintal et al. (2006) provided a scale to evaluate the degree of participants' uncertainty avoidance when solving problems and making decisions. Example items are 'It is important to have instructions spelled out in detail so that I always know what I am expected to do' and 'Rules and regulations are important because they inform me of what is expected of me.' (7-point scale, anchored at 1 as 'strongly disagree' and 7 as 'strongly agree'.)

\section{Self-efficacy}

Schwarzer and Jerusalem's (1995) 10-item scale provided an evaluation of participants' self-efficacy; example items are 'I can remain calm when facing difficulties because I can rely on my coping abilities', and 'I am confident that I could deal efficiently with unexpected events.' (7-point scale anchored from 1, 'strongly disagree', to 7 , 'strongly agree'.)

\section{Post-Decisional Regret}

We adapted the Schwartz et al. (2002) 5-item scale that identifies levels of postdecisional regret (PDR) to evaluate an individual's level of regret about the job choice decisions made. Five items tested the participants' attitudes about whether they thought there may have been better job choices than the one that they had chosen. The 
items are 'Whenever I make a job choice, I'm curious about what would have happened if I had chosen differently', 'Whenever I make a job choice, I try to get information about how the other alternatives turned out', 'If I make a job choice and it turns out well, I still feel like something of a failure if I find out that another job vacancy/position would have turned out better', 'When I think about how I'm doing in life, I often assess opportunities I have passed up', and 'Once I make a job decision, I don't look back.' (7-point scale: 1 as 'strongly disagree' and 7 as 'strongly agree'.)

\section{Need for Cognition}

We used the 18-item NFC scale developed by Cacioppo et al. (1983). Example items: 'I would prefer complex to simple problems', 'I try to anticipate and avoid situations where there is a likely chance I will have to think in depth about something', and 'I find satisfaction in deliberating hard and for long hours.' (7-point scale anchored from 1, 'extremely uncharacteristic', to 7, 'extremely characteristic'.)

\section{About Present Job - Met Expectations}

The Wotruba and Tyagi (1991) 25-item scale provided the evaluation of participants' perceptions of ME. Items that were included cover getting special awards or recognition, any individual effort required, the opportunity to make friends, respect from fellow colleagues, success related directly to initiative, attention and appreciation from supervisors, and development of work-required skills. Participants were instructed to think about their present job (the one they had accepted within the last six months) and the expectations that they had had about the job before they took the offer. They then compared their actual experiences with what they had expected before the offer had been accepted. (7-point scale anchored from 'My experience with this aspect (of my present job in the retail trade) is very much less than I expected' to a similar phrase ending with 'very much more than I expected'.)

\section{About Present Job - Job Satisfaction}

Participants also evaluated their satisfaction with their present job using five items adopted from Brayfield and Rothe (1951). This includes items such as 'I feel fairly 
satisfied with my present job' and 'I find real enjoyment in my work.' (7-point scale, anchored from 1, 'strongly disagree', to 7, 'strongly agree'.)

\section{About Present Job - Company Commitment}

To measure commitment of maximisers and satisficers to their present retail employment, the 4 items developed by Blau and Boal's (1987) study were adopted; example items are 'I find that my values and the company that I currently work for are very similar' and 'I feel myself to be part of this company.' (7-point scale: 1, 'strongly disagree', to 7, 'strongly agree'.)

\section{About Present Job - Intention to Quit}

Three items from Giacopelli, et al. (2013) were used, the items were initially developed by Cook et al. (1981) to evaluate respondents' intention to leave their present job: 'I feel that I could leave this job', 'I am actively looking for other retail trade jobs', and 'If I was completely free to choose, I would leave this job.' (7-point scale, anchored from 1, 'strongly disagree', to 7 , 'strongly agree'.)

\subsection{Procedure}

After participants had agreed with the ethical terms of the survey, instructions presented on the website helped guide them to answer the questions in section one regarding their opinions and attitudes towards their present job.

In the second section, participants indicated which job information source(s) they had ever used to search for retail trade job-related information in the past from eight recruitment information sources. These included online job discussion forums such as LinkedIn; online social media websites such as Facebook; searchable-online blogs; online job-searching sites such as Indeed.com; the company's official website; family or friends who have experience working in the sector or the company; recruiters; and newspaper advertisements. Participants were then instructed to indicate if they had ever received job invitations from a friend or family member who was an incumbent of the company. Also known as employee referral, this is considered different from 
the other listed eight sources because it is a source where jobseekers are approached with the information rather than searching for it. The information source list was derived from data collected for another study, where these sources were indicated by jobseekers as the most frequently used primary information sources to find job-related information in the retail trade. The second question asked participants to select from the same 9-item list about the information sources they used for searching for or getting job information related to their present job.

\section{Data Analysis and Results}

\subsection{Internal Consistency of the Scales}

All of the 10 variables displayed good internal consistency. The Cronbach's alphas were all greater than .70 (see Table 2 below). The mean self-reported maximising tendency score was 4.18 , which is very close to the mean $(M=4.20)$ of the Schwartz et al. (2002) dataset. It is worth noting that the mean score of uncertainty avoidance was below the median, suggesting that this sample of employees in the retail trade display the characteristics of not avoiding uncertainty situations. The possible reason is that retail trade employees need to interact with customers, and they cannot fully anticipate what type of customers they may meet. Thus, people who work in this sector need to accept uncertainty situations and try to solve customers' problems (Breaugh, 2013). Notwithstanding, previous research characterises the USA as a society that has a relatively higher tolerance for uncertainty than other cultures (Hofstede, 1994); the below mid-point score $(M=3.78)$ in this study could simply reflect this. On the other hand, the overall sample mean for self-efficacy is above the mid-point $(\mathrm{M}=4.48)$ and less than $30 \%$ of the sample rate themselves as lower than the mid-point on this variable. With self-efficacy scale items such as 'I am confident that I could deal efficiently with unexpected events', which indicate a degree of preparedness to deal with uncertainty, this pattern of results tentatively suggests future investigation of lower uncertainty avoidance and higher self-efficacy as characteristics in customer-facing retail employees. 
No significant relationships between demographic characteristics were found, except a positive relationship between work experience and wage level, an unsurprising and expected result. Notably, there were no relationships between maximising tendency and any socio-demographic measure, strongly suggesting that, in this sector, socio-demographic variables, particularly work experience, are not related to this decision-making style.

\subsection{Testing hypotheses}

Table 2 presents the Pearson correlations between the 10 variables. As expected, supporting H1, H2, H3, H5, and H6, the self-reported maximising tendency is positively correlated with the effort put into searching for job-related information $[\mathrm{r}(138)=.21, p<.01]$, uncertainty avoidance $[\mathrm{r}(138)=.22, p<.01], \operatorname{PDR}[\mathrm{r}(138)$ $=.26, p<.01]$, NFC $[\mathrm{r}(138)=.17, p<.01]$, and $\operatorname{ME}[\mathrm{r}(138)=.18, p<.05]$.

However, the statistics show that maximising tendency was not significantly correlated with self-efficacy $[\mathrm{r}(138)=.06, p>.05]$, job satisfaction $[\mathrm{r}(138)=-.07, p$ $>.05]$, company commitment $[\mathrm{r}(138)=-.04, p>.05]$, or intention to quit $[\mathrm{r}(138)$ $=.01, p>.05]$; therefore, $\mathrm{H4}, \mathrm{H7a}, \mathrm{H7b}$, and $\mathrm{H7c}$ were not supported.

--- Table 2 about here ---

\subsection{Follow-up analyses}

The predicted overall differences between maximisers and satisficers for job satisfaction, company commitment, and intentions to quit were not supported. Previous research indicates positive outcomes for employee satisfaction and retention when employees have more realistic job expectations and/or higher met job expectations. With this in mind, a series of follow-up ANCOVA test considered the joint effects of decision-making style and ME (split at mean into lower and higher met expectations or into three ascending groups at 33 and 66 percentile), while controlling for PDR. 
For job satisfaction, the role of ME was investigated by partitioning at low, medium, and high levels of ME by percentiles. A 2 × 3 ANCOVA showed a significant interaction between decision-making style and level of $\operatorname{ME}[\mathrm{F}(1,133)=$ $3.14, p<.05, \eta p 2=.045$ ] (see figure 1). Satisficers do have higher levels of job satisfaction but only at higher levels of $\mathrm{ME}\left[\mathrm{M}_{\text {maximiser }}=4.95 ; \mathrm{M}_{\text {satisficer }}=5.93, \mathrm{t}(43)\right.$ $=2.51, p<.05]$. Lower levels of ME are associated with lower levels of job satisfaction for both groups, but satisficer job satisfaction levels rise with stronger ME while maximiser levels do not continue to rise past moderate ME.

--- Figure 1 about here ---

For intention to quit, a 2 × 2 ANCOVA showed a significant interaction at 95\% confidence level between decision-making style and level of $\mathrm{ME}[\mathrm{F}(1,135)=5.05, p$ $<.05, \eta \mathrm{p} 2=.036]$. At lower ME maximisers are more likely to report intentions to quit than satisficers $\left[\mathrm{M}_{\text {maximisers }}=4.73, \mathrm{M}_{\text {satisficer }}=4.37, \mathrm{t}(24)=2.04, p<.05\right.$, one-tailed); at higher $\mathrm{ME}$ there is no significant difference $\left[\mathrm{M}_{\text {maximisers }}=3.94, \mathrm{M}\right.$ satisficer $=4.12, \mathrm{t}(35)=.17, p>.05$, one-tailed] (see figure 2). Thus, satisficers do have lower intentions to quit than maximisers but only at lower ME (note that satisficers show no significant difference in leaving intentions between low and high ME and that all reported intentions to quit are near or above the mid-point).

--- Figure 2 about here ---

For company commitment, the 2 × 2 ANCOVA results, although following the trend in the latter two analyses towards differences by levels of ME does not show a significant interaction $[\mathrm{F}(1,135)=.27, p>.05, \eta p 2=.002]$. However, at lower ME, a one-sample t-test shows a significantly lower level of company commitment for maximisers than for satisficers $\left[\mathrm{M}_{\text {maximiser }}=3.56 ; \mathrm{M}_{\text {satisficer }}=3.98, \mathrm{t}(27)=1.98, p\right.$ $<.05$, one-tailed] (see figure 3).

--- Figure 3 about here ---

Overall the pattern emerges that, although there is moderation of direct job outcome variables by level of $\mathrm{ME}$ in the direction of the $\mathrm{H} 7 \mathrm{a}, \mathrm{H} 7 \mathrm{~b}$, and $\mathrm{H} 7 \mathrm{c}$, the most negative effects are confined to the group of maximisers having lower ME for 
intention to quit and company commitment. For job satisfaction, the lower job satisfaction for maximisers compared to satisficers is restricted to high levels of ME and may be a reflection of the accuracy of (low) maximiser expectations of retail work; however, pre-choice levels of expectations were not measured.

\subsection{The Use of Job-related Information Sources}

For testing H8, a median split was used to differentiate between maximisers and satisficers for analysis of the second section. The median of 4.18 is close to that in previous research (e.g., 4.20 in Schwartz et al.'s (2002) dataset). Fisher's Exact Test was adopted because some cells had expected count less than 5 (Fisher, 1935). The results revealed that, compared to satisficers, significantly more maximisers used online blogs (41\% vs 22\%) [ $p<.05]$, online job discussion forums (55\% vs $42 \%)$ [ $p$ $<.1]$, and online job-searching sites $(91 \%$ vs $82 \%)[p<.1]$ to find job-related information. More satisficers made enquiries through their families or friends ( $97 \%$ vs $91 \%)[p<.1]$; therefore, $\mathbf{H 8}$ was supported.

Moreover, the results suggest that the traditional advertisement is still a high-frequency source of job information even if viewed in digital rather than newspaper format on job-search websites or company websites. The informal sources through friends and family also remain extremely popular, with over $90 \%$ of respondents reporting using these sources. Other information sources, such as discussion forums, blogs, and social media are popular but have not superseded the more traditional formats as yet, even informal information from friends and family. Many jobseekers consulted their friends and families if they had work experience in the sector. This may be because friends and family represent the more trusted 'close ties' source of job information (Granovetter, 1983) and formats such as discussion forums are more likely to be sources of, to some extent, less credible 'weak tie' information. However, taken together, the use of various social networks indicates that personal social networking is becoming an important information source for jobseekers that is facilitated by digital media during the job-seeking process.

Approximately $27 \%$ of the jobseekers in this sector were invited initially by incumbents in their social networks, indicating that, although employee referral is considered to be an effective source for initial alerting of prospective retail employees 
to job openings (Breaugh, 2013), it is not the norm for jobseekers in this study, and they are still heavily using/combining with other sources of information. We could be observing the effects of the online nature of the sample, in that they have easier, faster access to more sources of information and may be proactive job information seekers, whilst employee referral is a more passive undertaking.

--- Table 3 about here ---

In the second question, participants were asked to choose the sources that they used for searching for job-related information about their present job. On average, maximisers approached 4.7 job-related information sources and satisficers used approximately 2.2 sources; maximisers clearly invested more effort in the use of information sources than satisficers. Online job-searching sites, the company's website, family/friends, and the newspaper were still the most popular and frequently used sources that jobseekers reported, thereby supporting the results of the first question (see Table 4).

--- Table 4 about here ---

\section{Conclusions and Discussion}

Within the retail trade, companies face challenges in attracting jobseekers and widening their application pool. Existing research (e.g., Schwartz et al., 2002) suggests that maximisers' characteristics of high self-standards and pursuit of the 'best' solution lead them to delay decision-making and so, when deadlines approach, they are prone to making decisions under pressure that are less likely to match their standards for complete consideration. Maximisers are also more prone to experiencing PDR than satisficers, perhaps heightened when taking pressured decisions in which they may have less confidence. The present study focused on job decisions in the retail trade, finding no simple overall difference in satisfaction with job decisions between jobseekers who adopted a maximiser style or a satisficer style in their latest job choices within the last six months. For these respondents, who all work in retail, initially it appeared that maximisers have no higher intentions to quit than satisficers. Consequently, retail trade companies need not worry on these grounds about jobseekers who adopt a maximising approach when making decisions. 
Furthermore, maximisers report higher ME than satisficers; this might be credited to the effort that they put into searching for job-related information from more sources. Indeed, the follow-up analysis revealed that a majority of maximisers had their expectations met in this sample. The expectations do not have to be high; it is the confirmation of those expectations that is important. Low expectations met will result in less disappointment than high expectations not met. The results support this view; when maximisers' reactions to $\mathrm{ME}$ are considered, those with low $\mathrm{ME}$ are more likely to consider leaving than those with higher ME. However, satisficers show no significant difference in leaving intentions between low and high ME. So, to the extent that maximisers put in more effort and form more accurate expectations, likelihood to quit is a function of a difference between maximisers and satisficers on reactions to ME. Effort in building expectations may make these cognitions more accurate, or may increase the salience, or both, but whatever the cognitive underpinnings, if maximisers can be presented with and believe accurate expectations of the job, they seem to show higher company commitment and are less likely to intend to leave than if their expectations are not met. The danger lies in less accurate and unmet expectations, where they have lower company commitment and are more likely to consider leaving than satisficers. Maximisers report significantly lower job satisfaction ratings at high levels of met expectations than satisficers, but the previous results for intentions to quit indicate that this lower satisfaction is not turned into higher intentions to quit than satisficers at this level. This is probably due to the nature of jobs in the retail trade in that most of the jobs have some drawbacks (Rhoads et al., 2002). Both maximisers and satisficers may understand that working in this sector they will have to compromise on job choice, especially if they have locational or other restrictions on where they can work. Paradoxically, the context of restrictions on choice and time-pressured decisions may actually allow people to reduce any cognitive dissonance arising from the contradiction between PDR and their decision to take, or stay in, their present job. Attributions of external forces beyond their control as in some way responsible for the decision allow people to rationalise decisions and reduce dissonance (Gosling, Denizeau, and Oberl, 2006). This makes it possible for maximisers to hold the contradictory conditions of still scanning for the 'perfect' position even if relatively satisfied with and having no greater intentions than satisficers to leave their present job. 
Contrary to our expectation, satisficers actually showed no significantly higher levels of self-efficacy than maximisers. However, the mean self-efficacy score was above the mid-point $\left(\mathrm{M}_{\text {self-efficacy }}=4.48\right)$. This suggests that most employees who decided to specialise in the retailing industry show confidence in dealing with all kinds of (not limited to work-related) unexpected situations. We venture this may be because employees in the retail trade have to face a variety of customers and need to solve unexpected problems (Tyagi, 1999). Therefore, self-efficacy is high among employees in the retail trade, whether maximiser or satisficer. From these responses, most jobseekers in this sample seemed ready to take the challenge when they decided to join this sector. However, based on the present dataset, we cannot certainly conclude if this is because of the sector issue (is this a phenomena in the retail trade?) or the decision type issue (is this only in the job decisions?); future research may consider investigating more by comparing participants from different sectors and comparing when maximisers and satisficers are facing different decisions.

This study explored a group of participants that specifically work in a sector with a relatively lower average income and longer work hours compared to the existing studies that adopted student samples (e.g., Iyengar et al., 2006) or the general population (e.g., Lai, 2011). The variance in work-related outcomes to those expected and nuanced response to ME raises the possibility that, although decision-making styles may be chronically engaged, outcomes may vary with context. Further, although the basic notion of the classification remains the same (e.g., maximisers still put more effort into information search and show high PDR when faced with compromising deadlines), in a specific group of people or situation, the two decision-making style groups may react differently. Future research should investigate whether there are boundary conditions on decision-making style.

Furthermore, the results show that maximisers and satisficers have different preferences in using recruitment information sources to obtain job-related information. Maximisers are more likely to approach information sources where weaker relationships might be expected (weak ties), such as searchable-online blogs, whereas satisficers acquire job-related information from close relationship (strong tie) sources such as close friends and family. Consequently, companies need to carefully manage information sources to attract both maximisers and satisficers to optimise the 
candidate pool, especially with a view to providing realistic expectations. For instance, monitoring and replying to discussion topics as this may help provide maximisers with the information they need. Furthermore, adding recruitment activities on Facebook fan pages may attract more satisficers and their friends to join the activities and enable them to know more about the company.

Advertisements still seem a frequently used information source for both maximisers and satisficers in this sector. Previous research on advertisement messages indicates their effectiveness is not as good as other recruiting methods, such as employee referral (e.g., Ryan et al., 2005). Nevertheless, in this study, over $70 \%$ of the sample of retail employees reported that they had read advertisement messages to find information on job positions, and over $60 \%$ of the samples of retail employees indicated that they had used this source to get job information in the past six months. This result strongly suggests that, by carefully designing the content of the advertisement, companies can better attract and sustain jobseekers' interest in the job vacancy and promote realistic expectations. Further, relatively few in this sample of online participants reported receiving job invitations passively from people they knew as incumbents of the company. Relying on employee referral as the main recruitment source could lead employers to miss the chance of recruiting talented and qualified jobseekers who are not included in the referral network (Finneran and Kelly, 2003), and this study indicates that online resources can extend the reach of job advertising as so few relied on personal contacts.

There are some limitations that need to be acknowledged. Firstly, although Wotruba and Tyagi (1991) propose that ME is a different type of construct from those explored previously, in that ME involves a process rather than a specific set of variables defined in a particular domain, asking the employees to reflect on their past feelings may introduce error. Future studies might consider establishing other research designs or measures to avoid this. In addition, although the samples recruited were more specific in the nature of the participants compared to other research and allow at least some tentative inferences about relationships between the nature of decision making, retail employee recruitment, and work related outcomes, the sample size of this study compared to the retail workforce is relatively small. Although the sample shows some representativeness to features of the retail trade, it is an online 
sample in a trade where there may be groups with less or no Internet experience or exposure; thus, future research might focus on a larger sample that includes such groups. That said, the most rapidly growing and most widely available digital access is via the mobile phone; future research should also explore the effect of this platform on recruitment information sources. Another limitation that needs to be addressed is that the respondents of the present study are from different types of stores. One argument is that this spreads the influence of different treatments such as salary and health care on different styles of decision-makers' perceived attitudes towards their jobs. However, some companies do provide relatively generous benefits to their employees, but in this study we cannot test whether different decision-making style adopters may actually differ by the benefits that they received. Future studies may consider comparing whether 'company' and 'benefit' could be moderators that affect maximisers' and satisficers' perceptions towards their present jobs. Furthermore, this research did not evaluate an employee's actual (post-hire) performance, which future studies might also evaluate for differences between individual decision-making styles.

This study is the initial stage of a discussion of the issues of decision-making style in recruitment research. Additional questions that arise from these findings are waiting to be answered by further investigations into the effects of different information content within different sources on maximisers and satisficers; for example, a newspaper advertisement might contain mainly 'hard information' such as salary and work location whereas social media websites provide more personal-experience-based 'soft information' on the social working environment. Whether maximisers and satisficers have different information needs and preferences and how companies can provide information to satisfy the needs of both are key practical issues. Moreover, most of the organisations aim to avoid jobseekers receiving negative information, which may damage the company's reputation and decrease the jobseeker's willingness to join the organisation. However, this study shows the hidden dangers of not providing realistic information and the question remains: do maximisers and satisficers react differently to the message valence? Is it possible that a certain amount of negative information may not be sufficient to dissuade satisficers from applying for a vacancy, because a good-enough position would be able to satisfy their needs? Companies need to carefully evaluate how they 
can design an advertisement message that satisfies both maximiser and satisficer needs.

Recruiting staff is an integral part of any business. Researchers have invested heavily in recruitment research for over six decades; however, reporting of the full exploration and testing of this individual difference is still low. It is believed that this exploratory study of the decision-making style in recruitment will attract further attention from researchers and practitioners.

\section{REFERENCES}

Bandura, A. (1977), "Self-efficacy: toward a unifying theory of behavioral change", Psychological Review, Vol. 84 No. 2, pp. 191-215.

Blau, G. J. and Boal, K. B. (1987), “Conceptualizing how job involvement and organisational commitment affect turnover and absenteeism", Academy of Management Review, Vol. 12 No.2, pp. 288-300.

Blau, G. J. (1993) "Further exploring the relationship between job search and voluntary individual turnover", Personnel Psychology, Vol. 46 No. 2, pp. 313-330.

Brayfield, A. H. and Rothe, H. F. (1951), “An index of job satisfaction”, Journal of Applied Psychology, Vol. 35 No.5, pp. 307-311.

Breaugh, J. A. and Starke, M. (2000), "Research on employee recruitment: so many studies, so many remaining questions", Journal of Management, Vol. 26 No.3, pp. $405-434$.

Breaugh, J. A. (2013), “Employee recruitment”, Annual Review of Psychology, Vol. 64 pp. 389-416.

Buhrmester, M., Kwang, T. and Gosling, S. D. (2011), “Amazon's mechanical turk: a new source of inexpensive, yet high-quality, data?", Perspectives on Psychological Science, Vol. 6 No.1, pp. 3-5.

Cable, D. M. and Turban, D. B. (2001), "Establishing the dimensions, sources and value of job seekers' employer knowledge during recruitment", Research in Personnel and Human Resources Management, Vol. 20, pp. 115-163.

Cacioppo, J. T., Petty, R. E., and Morris, K. J. (1983), "Effects of need for cognition on message evaluation, recall, and persuasion", Journal of Personality and Social Psychology, Vol. 45 No. 4, pp. 805-818. 
Chowdhury, T. G., Ratneshwar, S., and Mohanty, P. (2009), “The time-harried shopper: Exploring the differences between maximizers and satisficers", Marketing Letters, Vol. 20 No. 2, pp.155-167.

Cook, J. D., Heptworth, S. J., Wall, T. D., and Warr P. B. (1981), “The experience of work: a compendium and review of 249 measures and their use", Academic Press New York.

Diener, E., Emmons, R. A., Larsen, R. and Griffin, S. (1985), "The satisfaction with life scale", Journal of Personality Assessment, Vol. 49 No. 1, pp. 71-75.

Driver M.J. and Mock T.J. (1975), "Human Information Processing, Decision Style Theory, and Accounting Information Systems", The Accounting Review, Vol. 50 No. 3, pp. 490-508.

Driver, M.J., and Streufert, S. (1969), "Integrative complexity: An approach to individuals and groups as information processing systems", Administrative Science Quarterly, Vol. 14, pp. 272-285.

Escalas, J.E. (2007), "Self-Referencing and Persuasion: Narrative Transportation Versus Analytical Elaboration", Journal of Consumer Research, Vol. 33, pp. $421-429$.

Finneran, L. and Kelly, M. (2003), "Social networks and inequality", Journal of Urban Economics, Vol. 53 No. 2, pp. 282-299.

Fiske, S., \& Taylor, S. (1984), Social cognition. Reading, Mass.: Addison-Wesley Pub. Co.

Fisher, R. A. (1935), The Design of Experiments, Oliver \& Boyd, Edinburgh.

Giacopelli, N. M., Simpson, K. M., Dalal, R. S., Randolph, K. L. and Holland S. J. (2013), "Maximizing as a predictor of job satisfaction and performance: a tale of three scales", Judgment and Decision Making, Vol. 8 No.4, pp. 448-469.

Griffin, E. (2006), A first look at communication theory. Boston: McGraw-Hill.

Gillespie, M. A. and Highhouse, S. (2008), "Are maximisers really unhappy? The measurement of maximizing tendency", Judgment and Decision Making, Vol. 3 No. 5, pp. 364-370.

Gosling, P., Denizeau, M., and Oberl, D. (2006), "Denial of responsibility: A new mode of dissonance reduction", Journal of Personality and Social Psychology, Vol. 90, pp. 722-733.

Granovetter, M., (1983), "The strength of weak ties: A network theory revisited", Sociological theory, Vol. 1, pp. 201-233. 
Gruszka, A., Matthews, G., and Szymura, B. (2010), Handbook of individual differences in cognition. New York: Springer.

Heider, F. (1958), The psychology of interpersonal relations. New York: Wiley.

Hill, R. E., 1970. New look at employee referrals as a recruitment channel. Personnel Journal, 49, pp.144-148.

Hofstede, G. H. (1994), "Cultures and organisations, software of the mind", Administrative Science Quarterly, Vol. 38, pp. 132-134.

Iyengar, S. S., Wells, R. E. and Schwartz, B. (2006), "Doing better but feeling worse looking for the "best" job undermines satisfaction", Psychological Science, Vol. 17 No. 2, pp. 143-150.

Jain, K., Bearden, J. N., and Filipowicz, A. (2013), "Do maximizers predict better than satisficers?", Journal of Behavioral Decision Making, Vol. 26 No 1, pp. $41-50$.

Judge, T.A., \& Cable, D.M. (1997), "Applicant personality, organisational culture and organisation attraction”, Personnel Psychology, Vol. 50 No. 2, pp. 359-394.

Lai, L. (2011), "Maximizing and customer loyalty: Are maximizers less loyal?", Judgment and Decision Making, Vol. 6 No. 4, pp. 307-313.

Misuraca, R. and Teuscher, U. (2013), “Time flies when you maximise-maximisers and satisficers perceive time differently when making decisions", Acta Psychologica, Vol. 143 No. 2, pp. 176-180.

Nenkov, G. Y., Morrin, M., Ward, A., Schwartz, B., and Hulland (2008), “A short form of the maximization scale: factor structure, reliability and validity studies", Judgment and Decision Making, Vol. 3 No. 5, pp. 371-388.

O'Reilly III, C. A., Caldwell, D. F. and Barnett, W. P. (1989), "Work group demography, social integration, and turnover", Administrative Science Quarterly, Vol. 34, pp. 21-37.

Parker, A. M., Bruine De Bruin, W. and Fischhoff, B. (2007), "Maximisers versus satisficers: decision-making styles, competence, and outcomes", Judgment and Decision Making, Vol. 2 No. 6, pp. 342-350.

Polman, E. (2012), "Self-other decision making and loss aversion", Organisational Behavior and Human Decision Processes, Vol. 119 No. 2, pp. 141-150.

Quintal, V., Lee, J. and Soutar, G. (2006), “Attitudes towards risk and uncertainty: suggested scales", available at: http://www.anzmac.org/conference_archive/ 2006/documents/Quintal_Vanessa.pdf 
Raymond, T. and Mjoli,T.Q. (2013), "The relationship between job involvement, job satisfaction and organizational commitment among lower-level employees at a motor-car manufacturing company in East London, South Africa", J. Bus. Econ. Manage. Vol. 1 No.2, pp. 25-35.

Rhoads, G. K., Swinyard, W. R., Geurts, M. D. and Price, W. D. (2002), "Retailing as a career: a comparative study of marketers", Journal of Retailing, Vol. 78 No. 1, pp. 71-76.

Ryan, A. M., Horvath, M. and Kriska, S. D. (2005), "The role of recruiting source informativeness and organisational perceptions in decisions to apply" International Journal of Selection and Assessment, Vol. 13 No. 4, pp. 235-249.

Schwartz, B., Ward, A., Monterosso, J., Lyubomirsky, S., White, K. and Lehman, D. R. (2002), "Maximizing versus satisficing: happiness is a matter of choice" Journal of Personality and Social Psychology, Vol. 83 No. 5, p. 1178-1197.

Schwartz, B. and Ward, A. (2004), Doing Better but Feeling Worse: The Paradox of Choice, in Positive Psychology in Practice (eds P. A. Linley and S. Joseph), John Wiley and Sons, Inc., Hoboken, NJ, USA

Schwarzer, R., and Jerusalem, M. (1995), Generalized Self-Efficacy scale', In J. Weinman, S. Wright, and M. Johnston, Measures in health psychology: A user's portfolio. Causal and control beliefs (pp. 35-37). Windsor, UK: Nfer-Nelson

Simon, H. A. (1955), “A behavioral model of rational choice”, The Quarterly Journal of Economics, Vol. 69 No. 1, pp. 99-118.

Simon, H. A. (1975). "Style in design". In C. Eastman (Ed.), Spatial synthesis in computer-aided building design, 9, 287-309. New York: John Wiley \& Sons.

Sparks, E. A., Ehrlinger, J. and Eibach, R. P. (2012), "Failing to commit: maximisers avoid commitment in a way that contributes to reduced satisfaction", Personality and Individual Differences, Vol. 52 No. 1, pp. 72-77.

Turner, B., Rim, H. B., Betz, N. E. and Nygren, T. E. (2012), "The maximization inventory", Judgment and Decision Making, Vol. 7 No. 1, pp. 48-60.

Tyagi, R. (1999), "A Characterization of Retailer Response to Manufacturer Trade Deals", Journal of Marketing Research, Vol. 36 No. 4, pp. 510-516.

Wotruba, T. R. and Tyagi, P. K. (1991), "Met expectations and turnover in direct selling", Journal of Marketing, Vol. 55, pp. 24-35. 
Figure 1: Job satisfaction by level of ME and decision-making style

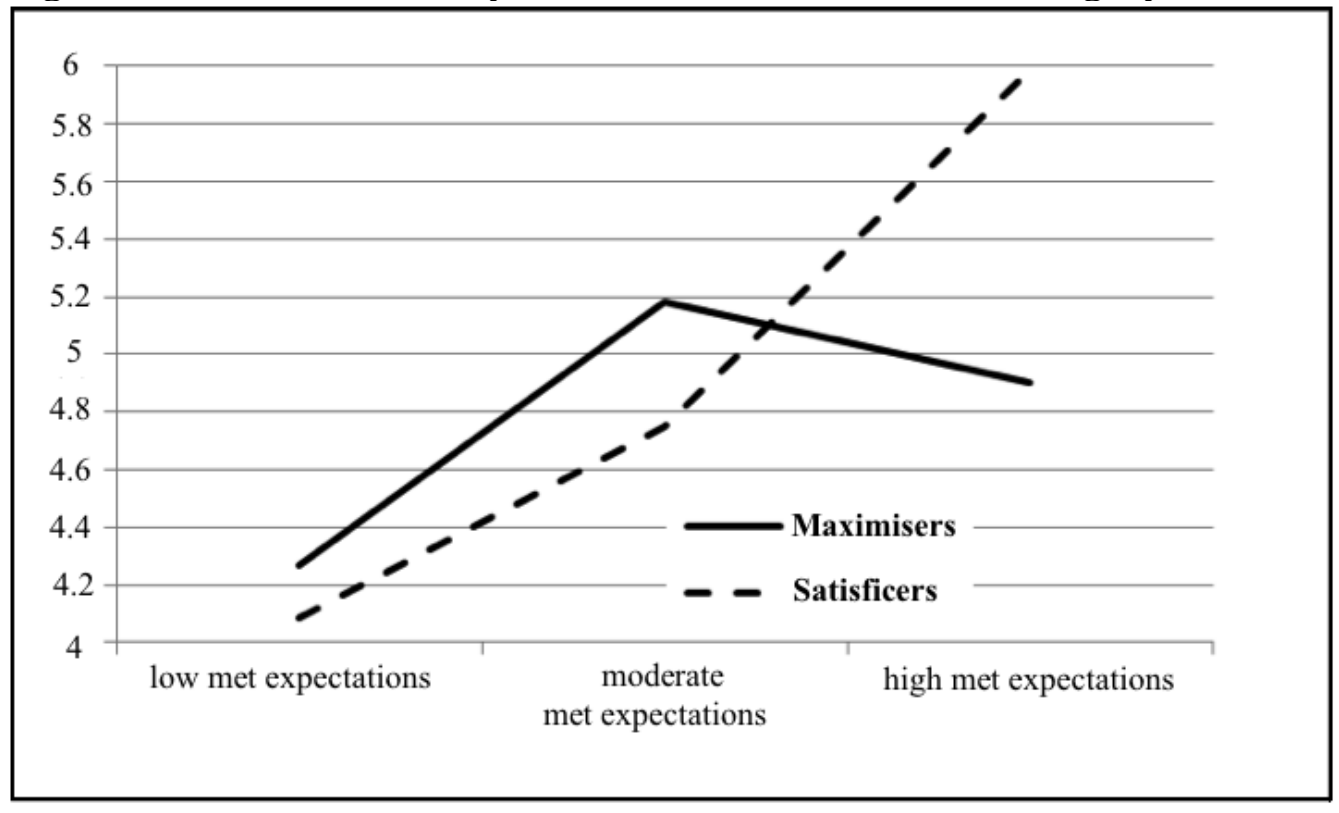


Figure 2: Intentions to quit by level of ME and decision-making style

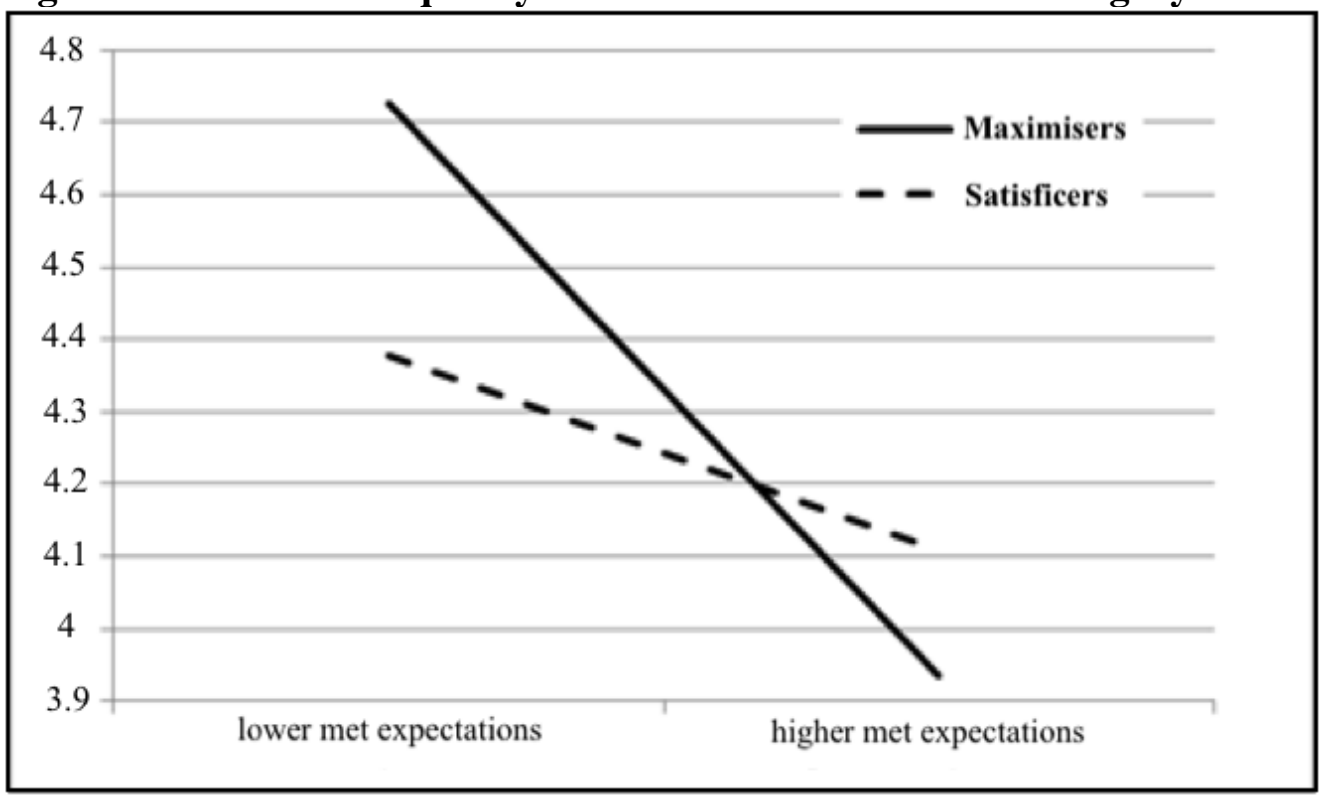




$$
1=
$$


Table 1. Demographics $(N=140)$

\begin{tabular}{|c|c|c|c|}
\hline \multicolumn{2}{|l|}{ Gender } & \multicolumn{2}{|l|}{ Age group } \\
\hline Male & $52 \%$ & $19-25$ & $22 \%$ \\
\hline Female & $48 \%$ & $26-32$ & $26 \%$ \\
\hline \multicolumn{2}{|l|}{ Education } & $33-39$ & $19 \%$ \\
\hline High School & $43 \%$ & $40-46$ & $20 \%$ \\
\hline University/College & $41 \%$ & $47+$ & $13 \%$ \\
\hline Postgraduate & $16 \%$ & & \\
\hline \multicolumn{2}{|c|}{ Length of Experience in Retail Trade } & \multicolumn{2}{|l|}{ Monthly Salary } \\
\hline Less than 1 year & $9 \%$ & Under $\$ 1,000$ & $14 \%$ \\
\hline $1-2$ years & $22 \%$ & $\$ 1,001-\$ 3,000$ & $53 \%$ \\
\hline $2-3$ years & $15 \%$ & $\$ 3,001-\$ 5,000$ & $23 \%$ \\
\hline $3-4$ years & $20 \%$ & $\$ 5,001-\$ 7,000$ & $6 \%$ \\
\hline $4-5$ years & $13 \%$ & $\$ 7,001-\$ 9,000$ & $4 \%$ \\
\hline Over 5 years & $21 \%$ & & \\
\hline
\end{tabular}


Table 2. Decision-making styles and other variables

\begin{tabular}{|c|c|c|c|c|c|c|c|c|c|c|c|c|}
\hline & \multirow[b]{2}{*}{ Mean } & \multirow[b]{2}{*}{ S.D. } & \multicolumn{10}{|c|}{ Pearson Correlations } \\
\hline & & & $(1)$ & $(2)$ & $(3)$ & $(4)$ & $(5)$ & $(6)$ & $(7)$ & $(8)$ & $(9)$ & $(10)$ \\
\hline (1) Maximizing Tendency & 4.18 & .96 & .80 & & & & & & & & & \\
\hline (2) Effort & 4.60 & 1.40 & $.21^{* *}$ & .94 & & & & & & & & \\
\hline (3) Uncertainty Avoidance & 3.78 & 1.43 & $.22^{* *}$ & .02 & .89 & & & & & & & \\
\hline (4) Post-Decisional Regret & 4.07 & 1.33 & $.26^{* *}$ & .09 & -.13 & .86 & & & & & & \\
\hline (5) Need for Cognition & 4.67 & .83 & $.17^{* *}$ & $.77^{* *}$ & $.41^{* *}$ & -.11 & .74 & & & & & \\
\hline (6) Self-Efficacy & 4.48 & .94 & .13 & .06 & $.32^{* *}$ & $-.22^{* *}$ & $.39^{* *}$ & .95 & & & & \\
\hline (7) Met Expectation & 4.76 & 1.16 & $.18^{*}$ & $.91^{* *}$ & -.02 & .07 & $.78^{* *}$ & .09 & .94 & & & \\
\hline (8) Job Satisfaction & 4.79 & 1.56 & -.07 & $.22^{* *}$ & .07 & $-.17^{*}$ & $.34^{* *}$ & $.26^{* *}$ & $.25^{* *}$ & .92 & & \\
\hline (9) Company Commitment & 4.25 & 1.52 & -.04 & $.42^{* *}$ & -.05 & -.10 & $.45^{* *}$ & $.27^{* *}$ & $.40^{* *}$ & $.61^{* *}$ & .89 & \\
\hline (10) Intention to Quit & 4.27 & .89 & .01 & $-.18^{*}$ & $-.16^{*}$ & $.30^{* *}$ & $-.40^{* *}$ & $-.53^{* *}$ & -.19 & $-.29^{* *}$ & $-.35^{* *}$ & .82 \\
\hline
\end{tabular}

Internal consistency reliabilities (Cronbach's alpha) for each measure are reported in the diagonals, in italics

Pearson Correlations $(\mathrm{N}=140) * p<.05, * * p<.01$ 
Table 3: Sources that have been used to get retail trade job-related information previously

\begin{tabular}{rrrrr}
\hline & \multicolumn{2}{c}{ Maximisers (total N=64) } & \multicolumn{2}{c}{ Satisficers (total N = 76) } \\
& $\mathrm{N}$ & $(\%)$ & $\mathrm{N}$ & $(\%)$ \\
\hline$(\mathbf{1})$ & $\mathbf{3 5}$ & $\mathbf{( 5 5 )}$ & $\mathbf{3 2}$ & $(\mathbf{4 2})$ \\
$(2)$ & 32 & $(50)$ & 43 & $(57)$ \\
$(\mathbf{3})$ & $\mathbf{2 6}$ & $\mathbf{( 4 1 )}$ & $\mathbf{1 7}$ & $(\mathbf{2 2})$ \\
$(\mathbf{4})$ & $\mathbf{5 8}$ & $\mathbf{( 9 1 )}$ & $\mathbf{6 2}$ & $\mathbf{( 8 2 )}$ \\
$(5)$ & 61 & $(95)$ & 67 & $(88)$ \\
$(\mathbf{6})$ & $\mathbf{5 8}$ & $\mathbf{( 9 1 )}$ & $\mathbf{7 4}$ & $(\mathbf{9 7})$ \\
$(7)$ & 31 & $(48)$ & 36 & $(47)$ \\
$(8)$ & 47 & $(73)$ & 59 & $(78)$ \\
\hline$(9)$ & 17 & $(27)$ & 22 & $(29)$ \\
\hline
\end{tabular}

(1) Online job discussion forums, (2) Online social media websites, (3) Online blogs, (4) Online job-searching sites, (5) (Online) company's official website, (6) Family/friends who have experience in working in the sector, (7) Recruiters, (8) Newspapers/Advertisement, (9) My friends/family came to me and invited me to join the company (work with them) - employee referral 
Table 4: The sources that were used to get job-related information for the present job/work (within six months)

Maximisers (total $\mathrm{N}=64$ )

Satisficers (total $N=76$ )

\begin{tabular}{rrrrr} 
& $\mathrm{N}$ & $(\%)$ & $\mathrm{N}$ & $(\%)$ \\
\hline$(1)$ & 26 & $(41)$ & 7 & $(9)$ \\
$(2)$ & 22 & $(34)$ & 24 & $(32)$ \\
$(3)$ & 18 & $(28)$ & 2 & $(3)$ \\
$(4)$ & 55 & $(86)$ & 25 & $(33)$ \\
$(5)$ & 58 & $(91)$ & 23 & $(30)$ \\
$(6)$ & 57 & $(89)$ & 32 & $(42)$ \\
$(7)$ & 22 & $(34)$ & 11 & $(14)$ \\
$(8)$ & 44 & $(69)$ & 40 & $(53)$ \\
\hline$(9)$ & 7 & $(11)$ & 6 & $(8)$ \\
\hline
\end{tabular}

Notes for serial numbers - see Table 3 